\title{
Nestmate recognition in defense against nest invasion by conspecifics during swarming in a one-piece nesting termite
}

Daniel Aguilera-Olivares ${ }^{1 *}$, José F. Rizo ${ }^{1}$, Camila Burgos-Lefimil ${ }^{1}$, Luis Flores-Prado² and Hermann M. Niemeyer ${ }^{1 *}$

\begin{abstract}
Background: In one-piece nesting termites, which nest and forage in a single piece of wood, soldier production increases during the swarming period, i.e. when the risk of invasion of their substrate and hence of their colony by dealates in search of a nesting substrate increases. In Neotermes chilensis, a one-piece nesting termite endemic to Chile, we hypothesized: i) that during swarming soldiers would defend their colony by showing higher aggressiveness toward non-nestmate than toward nestmate dealates, ii) that aggressiveness would negatively correlate with genetic relatedness of interacting soldier/dealate pairs and iii) that nestmate recognition would be based on differences in cues provided by cuticular compounds (CC) between nestmates and non-nestmate dealates.
\end{abstract}

Methods: The first hypothesis was tested using bioassays in which a soldier was confronted with a nestmate or a non-nestmate dealate; the second hypothesis by using microsatellites to assess genetic relatedness of the interacting pairs; and the third hypothesis using bioassays in which a soldier was confronted with a nestmate or a non-nestmate dead dealate with or without its CC and with dead dealates with interchanged CC between nestmate and non-nestmate.

Results: Soldiers were more aggressive toward non-nestmate than nestmate dealates, aggressiveness was inversely correlated with genetic relatedness of the interacting pair, and CC accounted for the differences in aggressiveness towards nestmate and non-nestmate dealates.

Conclusions: During swarming, soldiers of $\mathrm{N}$. chilensis protect their nest against invasion by non-nestmate conspecific dealates; discrimination is based on CC and aggressiveness correlates inversely with genetic relatedness of the interacting soldier/dealate pairs.

Keywords: Chemical communication, Neotermes chilensis, Kin recognition, Cuticular compounds, Aggressive behavior, Genetic relatedness

Abbreviations: CC, Cuticular compounds

\footnotetext{
* Correspondence: daguilera@abulafia.ciencias.uchile.cl; niemeyer@abulafia. ciencias.uchile.cl

${ }^{1}$ Departamento de Ciencias Ecológicas, Facultad de Ciencias, Universidad de

Chile, Casilla 653, Santiago, Chile

Full list of author information is available at the end of the article
} 


\section{Background}

Conspecific recognition plays a key role in the evolution of cooperative behavior e.g. $[1,2]$ and under a sociobiological context operates between different categories of organisms, e.g. between nestmates and non-nestmates, between individuals that share different degrees of relatedness or between organisms belonging to different castes. Nestmate recognition is widespread among eusocial insects and can be inferred from the outcome of the interaction between individuals from the same or different nests (or colonies) [3-6]. Chemical communication is the most ancient and widespread mode of communication in social insects and plays a significant role in nestmate recognition [7], an ability involved in the defense of colonies [8], particularly in situations where the likelihood of encounters with individuals from other colonies is high.

Termites are eusocial insects living in colonies. Several categories of termites have been proposed in relation to their nesting ecology and feeding habits [912]; main categories described are separate-piece nesters which nest and forage in different substrates and one-piece nesters which nest and forage in a single piece of wood [13]. Colonies of all types of termites contain at least three castes: reproductives whose main function in a mature colony is reproduction, true workers (or pseudergates) in charge of food searching, nest building and brood care, and soldiers involved in colony defense [13]. Immatures become true workers, a terminal caste, after the first molt, i.e., they are not able to develop into other castes, and are characteristic of separate-piece nesting termites $[13,14]$; while pseudergates may become soldiers, alates or they may spend their whole life as pseudergates depending on environmental conditions $[13,14]$.

The behavioral repertoire preceding the founding of a colony is similar in all termites [12]. During the warm season mature colonies produce alates of both sexes which disperse as swarms. Once they land, they lose their wings and give rise to dealates, which after choosing a potential mate search for a nesting substrate where they build a royal chamber, mate and oviposit [12, 15-17]. Potential substrates in the swarming area may already contain termite colonies which may then be invaded by incoming dealates. This calls for defense mechanisms in the colony which may be activated prior to the swarming period. It was recently shown that in the one-piece nesting termite Neotermes chilensis (Kalotermitidae), which uses dry scapes (stems of inflorescences) of Puya berteroniana (Bromeliaceae) as host [18], the ratio of soldiers to nonsoldiers within a colony was greater at the onset of the swarming period than in the non-swarming period, in multicolonial scapes (Aguilera-Olivares D, Palma V, Zapata V, Flores-Prado L, Niemeyer HM, submitted manuscript). This observation suggests that colony defense in $N$. chilensis is enhanced during swarming, a possible reason being to counteract the risk of invasion by dealates. Although invasion of nests by dealates in onepiece nesting termites has not been reported, it may be expected to occur based on the following facts: i) computed tomography studies have shown that galleries of $N$. chilensis are generally distributed along the scape closest to the bark, particularly in mature colonies (Aguilera-Olivares D, Palma V, Zapata V, Flores-Prado L, Niemeyer HM, submitted manuscript), an observation consistent with that reported in the one-piece nester Cryptotermes secundus (Kalotemitidae) [19]; ii) the galleries of $N$. chilensis occupy a substantial proportion of the volume of the scape (mean: $39.7 \%$; range: $17.4-63.9 \%$, unpublished results); iii) in the one-piece nester Incisitermes minorhence (Kalotermitidae), a termite similar in size to $N$. chilensis, dealates penetrate about $12 \mathrm{~mm}$ into the wood and spread about $15 \mathrm{~mm}$ along the main axis of the substrate, a considerable distance within the substrate, in order to build their royal chamber [20] and iv) in an experiment where scapes with $N$. chilensis colonies were brought to the laboratory during the swarming season and covered with a fine-mesh tissue in order to count emerging alates, we gathered evidence of the return of dealates to the scape after swarming; thus, in all instances $(\mathrm{N}=15)$ when emerged alates were not withdrawn after counting them and scapes were later dissected, dealates were found within the galleries. These observations suggest that penetration of dealates of N. chilensis to build their royal chamber during swarming is likely to cause invasion of existing galleries and hence encounters with resident soldiers. The defense capacity of soldiers against invading dealate conspecifics depends on their ability to recognize them as non-nestmates. Hence, experiments were performed with soldier/dealate pairs of $N$. chilensis aimed at testing the occurrence of nestmate recognition.

Furthermore, it has been repeatedly shown in separatepiece nesting termites that cuticular compounds (CC) play an important role in nestmate recognition e.g. [21-27]. Although this role has not yet been described in one-piece termites, we tested the possible involvement of CC in the interaction of soldiers and dealates of $N$. chilensis.

Lastly, since a negative correlation between degree of relatedness and intensity of aggression has also been reported in a separate-piece nesting termite [24], we tested the occurrence of such correlation with the data from the experiments mentioned above.

\section{Methods}

Study area and species

Field work was performed at Las Chilcas $\left(32^{\circ} 52^{\prime} \mathrm{S} ; 70^{\circ}\right.$ $52^{\prime} \mathrm{W}$ ) and laboratory work in Santiago, approximately $75 \mathrm{~km}$ south of the field site. N. chilensis is a drywood 
termite endemic to Chile between $c a .26-33.5^{\circ} \mathrm{S}$ [18] which in the study area uses dry scapes (cylindrical stems of inflorescences, ca. $10 \times 200 \mathrm{~cm}$, diameter $\mathrm{x}$ length) of Puya berteroniana (Bromeliaceae) as host, forming colonies containing up to 350 individuals. The plants show a patchy distribution at the site.

\section{Bioassays}

Scapes were severed from the rest of the plant in the field during the swarming season and brought to the laboratory in Santiago. Bioassays were set up to evaluate the occurrence of nestmate recognition of dealates by soldiers. Alates and soldiers were extracted and individually deposited inside 12-cm diameter Petri dishes whose bottom had been lined with filter paper. Once alates shed their wings forming dealates, one dealate individual was introduced in the experimental arena (a Petri dish where a soldier had remained for 20 min for acclimation) with a nestmate $(\mathrm{N}=10)$ or a non-nestmate $(\mathrm{N}=7)$ soldier. Once the dealate was introduced in the experimental arena, the bioassay started and was recorded for 15 min with a Sony ${ }^{\circ}$ Cybershot camera. The occurrence of behavioral events and the duration of behavioral states were evaluated through playback using the program JWatcher v1.0 [28]. Following similar studies with termites [8, 24, 29-32], ants [33], wasps [34] and bees [35], the behaviors of the soldier which derived from a recognition process were classified as aggressive (biting, grasping, opening jaws), alarm (drumming) and nonaggressive (antennating, backing up). Biting includes perforating the exoskeleton of the dealate, grasping refers to holding the oponent with the jaws without inflicting apparent damage, drumming consists in body vibrations against the substrate, antennation involves touching the oponent with the antennae, and backing up implies running away or backing up after contact. Two additional behaviors were observed which did not seem to derive from a recognition process: standing still and walking along the walls of the arena; they were not included in the analysis. Biting, grasping and opening of the jaws occurred as events which were analyzed as the number of times they were observed during each bioassay; the other behaviors corresponded to states which were analyzed as the total time they were performed during each bioassay.

Bioassays were also set up to evaluate the involvement of CC in nestmate recognition; they incorporated a live soldier and a nestmate or non-nestmate dead dealate. Dead dealates were subjected to the following treatments: i) with $C C$ : a dealate was killed by freezing for 5 min at $-20{ }^{\circ} \mathrm{C}(\mathrm{N}=8$ nestmates and $\mathrm{N}=7$ nonnestmates) thus retaining its own $C C$; ii) without $C C$ : a dead dealate which had been immersed in $250 \mu \mathrm{L}$ of pentane for $10 \mathrm{~min}$ to devoid it of its $\mathrm{CC}(\mathrm{N}=9$ nestmates and $\mathrm{N}=7$ non-nestmates); iii) chemical disguise: a nestmate dead dealate without its CC was coated with the $\mathrm{CC}$ extracted from a non-nestmate - thus, the dealate was physically a nestmate but chemically a non-nestmate of the live soldier - and vice-versa $(\mathrm{N}=10$ nestmates and $\mathrm{N}=10$ non-nestmates), and iv) control of chemical disguise: a control of the previous bioassay, where the dead dealate without its $\mathrm{CC}$ was coated with its own $\mathrm{CC}(\mathrm{N}=8$ nestmates and $\mathrm{N}=7$ non-nestmates). Behaviors of the soldier were observed and classified as above.

Each individual was used only in one bioassay. A total of 38 colonies were used, 12 for the bioassays with live termites and 26 for bioassays with a live soldier and a dead dealate. In the nestmate treatments, each interacting pair replicate came from a different colony. In the non-nestmate treatments, for each soldier/live or treated dealate combination only one soldier and one dealate were withdrawn from each of the colonies used; the colonies were selected haphazardly to set-up the interacting pair replicates. These precautions avoided pseudoreplication.

In both types of bioassays, the results from the two treatments were compared for each class of behaviors using the two-tailed $t$-test. When data did not fulfill normality and homoscedasticity conditions, the Mann-Whitney $U$-test was used [36]. To perform parametric analyses, ln-transformations were used for aggressive behaviors in the bioassay with live termites and in the control of chemical disguise bioassay with a dead termite, and SQRT-transformations were used for non-aggressive behaviors in the bioassay with live termites, for aggressive behaviors in the with $C C$ bioassay with a dead termite, and for alarm behaviors in all bioassys with a dead termite excepting the chemical disguise bioassay. Statistical analyses were performed with the program Statistica 7.0 [37].

\section{Genetic differences between individuals bioassayed}

Once a bioassay with live soldiers and dealates ended, termites were individually stored for genetic analysis in $70 \%$ ethanol. DNA was obtained from termites using the Qiagen DNeasy Blood \& Tissue kit. Genetic analyses were performed with microsatellites developed specifically for $N$. chilensis; microsatellite characterization and PCR conditions were as described earlier [38]. Relatedness between interacting individuals from each behavioral bioassay replicate was determined using the KINSHIP 1.3.1 software [39]. The relatedness degrees between nestmate and non-nestmate pairs were compared using two-tailed $t$-test. A Spearman Rank correlation was performed between relatedness degree and aggressive, alarm or non-aggressive behaviors between soldier and dealate pairs $(\mathrm{N}=17)$ using the program Statistica 7.0 [37]. 


\section{Results}

\section{Bioassays}

When soldiers were confronted with live dealates, the number of aggressive events of soldiers was significantly higher toward non-nestmate than toward nestmate dealates $\left(t_{15}=8.22 ; \mathrm{P}<0.001\right)$, while differences in the duration of alarm and non-aggressive behaviors between nestmates and non-nestmates were not significant (Fig. 1).

When soldiers were confronted with dead dealates with $C C$ the number of aggressive events of soldiers was significantly higher towards non-nestmate than toward nestmate dealates $\left(\mathrm{t}_{13}=-2.65 ; \mathrm{P}=0.02\right.$; Fig. $\left.2 \mathrm{a}\right)$; significance disappeared when dealates without $C C$ were used. In the chemical disguise treatment, the number of aggressive events was significantly higher toward nestmates that were chemical non-nestmates than toward nonnestmates that were chemical nestmates of the soldier $\left(\mathrm{U}_{10,10}=15.5 ; \mathrm{P}=0.01\right)$, while in the control of chemical disguise treatment the number of aggressive events was significantly higher towards non-nestmates than towards nestmates $\left(\mathrm{t}_{13}=-2.97 ; \mathrm{P}=0.011\right)$ (Fig. 2a). The duration of alarm behaviors did not differ between nestmate and non-nestmate combinations (Fig. 2b). Finally, the duration of non-aggressive behaviors did not differ significantly between nestmate and non-nestmate combinations except in the control of chemical disguise treatment where it was significantly higher $\left(\mathrm{t}_{13}=3.02 ; \mathrm{P}=0.009\right)$ between nestmates than between non-nestmates (Fig. 2c).

\section{Behavior and genetics}

Relatedness differed significantly $\left(\mathrm{t}_{15}=2.09 ; \mathrm{P}=0.045\right)$ between nestmates (mean $\pm \mathrm{SE}$ : $0.26 \pm 0.05$ ) and nonnestmates $(0.11 \pm 0.05)$. The number of aggressive behavioral events of soldiers towards nestmate and nonnestmate dealates were significantly and negatively correlated with genetic relatedness of the interacting pair (Spearman correlation: $\mathrm{r}=-0.604 ; \mathrm{P}=0.01$; Fig. 3 ); the duration of alarm and non-aggressive behaviors were not correlated with genetic relatedness.

\section{Discussion}

The outcome of bioassays involving nestmate and nonnestmate soldier/dealate pairs depended on the type of behavior observed. Alarm behaviors were performed for very short times and differences between non-nestmates and nestmates were not significant. The main function of alarm signals is to warn nestmates of potential threats [40]; however, under isolated bioassay conditions in which there are no nestmates to alert, alarm signals appear superfluous. Additionally, non-significant differences were found in non-aggressive behaviors between nestmate and non-nestmate dealates; this may be expected since to non-aggressive behaviors do not help against the attack of a dealate.

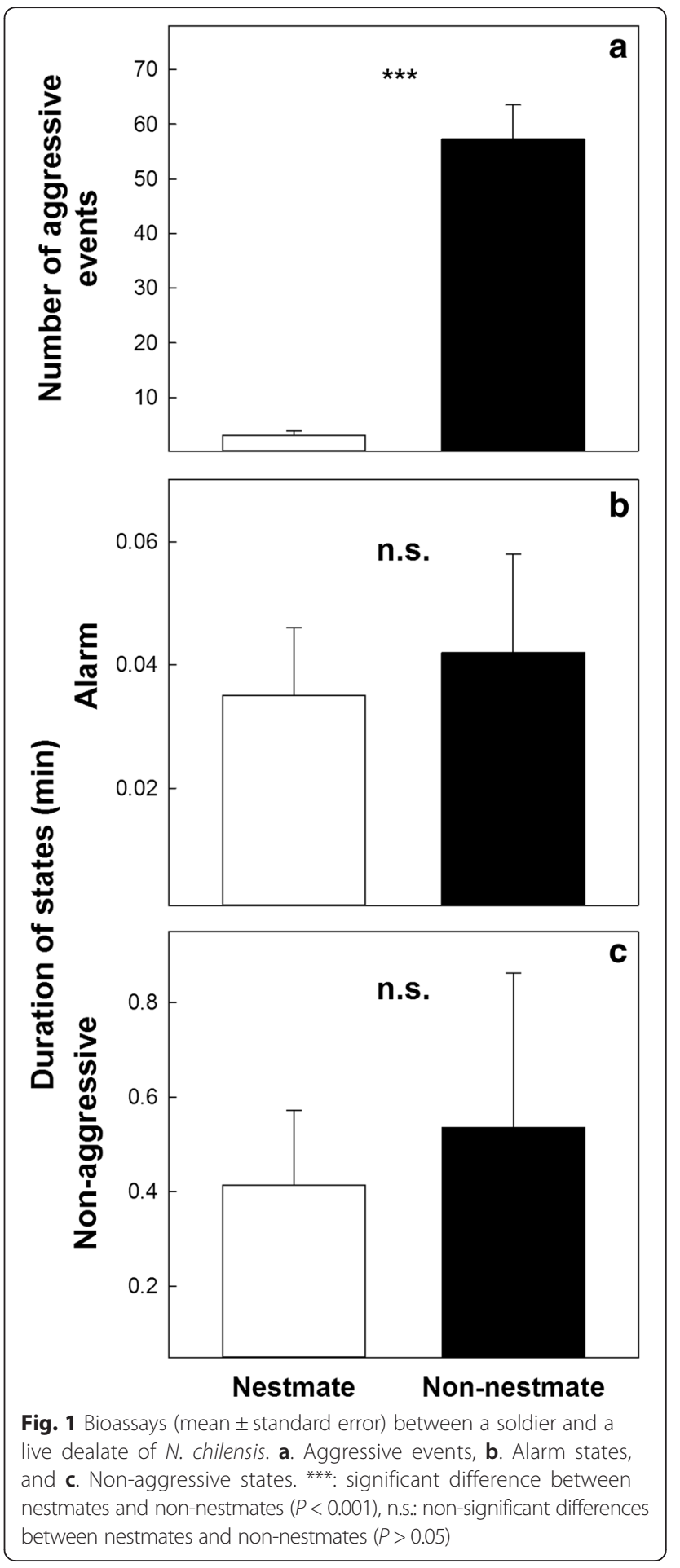

Soldiers of $N$. chilensis were more aggressive towards non-nestmate than nestmate dealates, showing that soldiers are able to discriminate between nestmate and non-nestmate dealates; thus, nestmate recognition is a trait present in soldiers of $N$. chilensis. Nestmate recognition has been also demonstrated in several species of separate-piece nesting termites where individuals encounter 


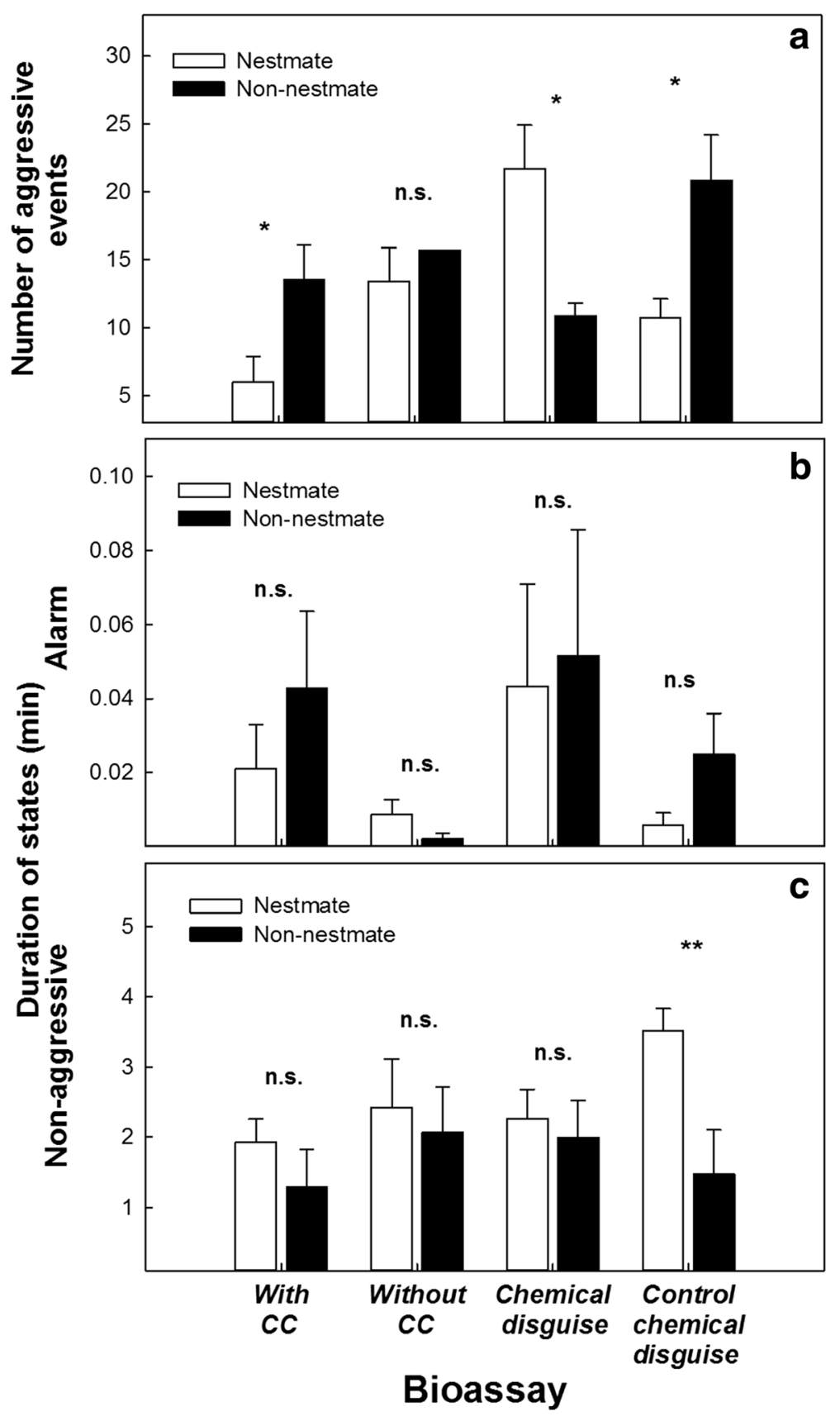

Fig. 2 Bioassays (mean \pm standard error) between a soldier and a dead dealate of $N$. chilensis. Treatments: with its own cuticular compounds (with CC); without cuticular compounds (without CC); with a cuticular compounds disguise coming from another dealate which was a nestmate or a non-nestmate of the soldier (chemical disguise); and a soldier confronting a dead dealate disguised with its own cuticular compounds (control of chemical disguise). a. Aggressive events, $\mathbf{b}$. Alarm states and $\mathbf{c}$. Non-aggressive states. ${ }^{*}=$ significant difference $(P<0.05) ;{ }^{*}=$ significant difference $(P<0.01)$; n.s.: non-significant differences $(P>0.05)$

individuals from another colony during foraging activities e.g. [24, 41-46]; in the one-piece nester Zootermopsis nevadensis (Termopsidae), intercolonial interactions resulted in agonistic behaviors leading to the killing of primary reproductives in a context of colonies sharing the nesting substrate [47]. Recently, Aguilera-Olivares et al. showed that $N$. chilensis soldiers were more aggressive toward non-nestmate than nestmate primary reproductives, pseudergates and soldiers [48].

Bioassays showed that when CC remained on a dead dealate, the interacting soldier was more aggressive toward a non-nestmate than a nestmate; however, when $\mathrm{CC}$ were washed away from the carcass, such difference disappeared; moreover, when the dealate was chemically 


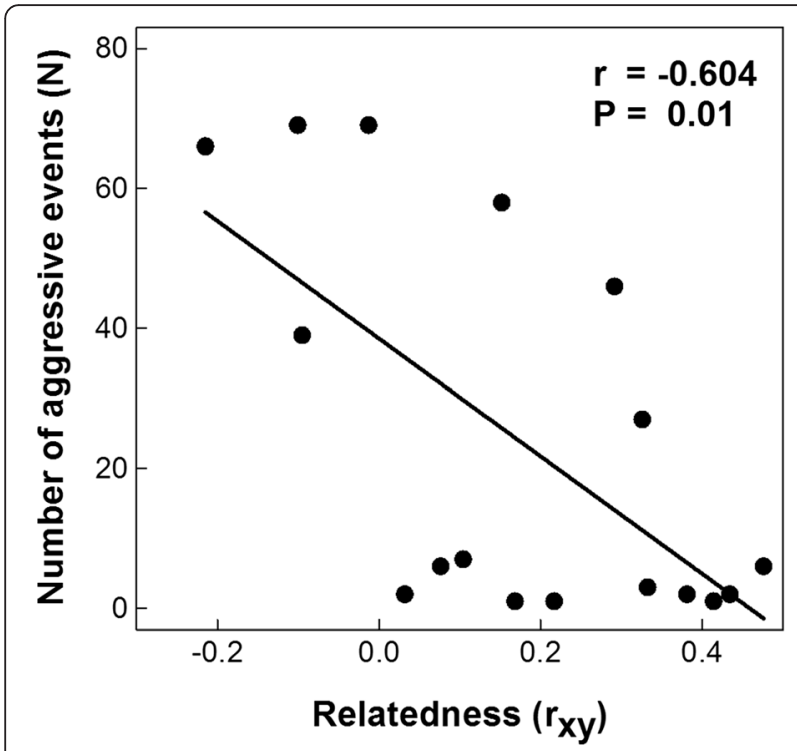

Fig. 3 Correlation between relatedness and aggressive behaviors of the soldier/dealate interacting pair

disguised the former differences were inverted, and when cuticular compounds were reinstituted to the owner dealate differences were reestablished. Mostly non-significant differences were found in alarm and non-aggressive behaviors in the chemical bioassays. When CC were restored to the original owner the duration of non-aggressive behaviors was higher towards nestmate than non-nestmates. These results show that $\mathrm{CC}$ play an important role in the nestmate recognition capacity of soldiers towards dealates of the one-piece termite $N$. chilensis; such role has been repeatedly shown in separate-piece nesting termites e.g. [21-27].

Aggressive behaviors between soldiers and dealates were negatively correlated with the degree of relatedness of the interacting pair. These results show that soldiers of $N$. chilensis were able to discriminate between dealates with different degrees of relatedness, suggesting kin recognition capacity. Given that the nesting substrate represents a limited resource for one-piece nesting termites in terms of space and food, it is expected that soldiers of $N$. chilensis defend their nesting resource and show aggression towards invading dealates. However, this aggression could be less intense when the interacting pair is more closely related. In other words, we propose that soldiers of $N$. chilensis are more willing to share their nesting resource with closely related individuals through kin recognition capacity. Related evidence has been reported in females of the bee Exoneura bicolor which exhibit social polymorphism. Thus, E. bicolor exhibits both solitary and aggregated nesting behaviors; in the latter case, aggregations occur between closely related females [49]. Interestingly, $N$. chilensis and $Z$. nevadensis, both one-piece nesting termites, reside in pieces of wood which may contain one or more separate colonies of the same termite species (47; Aguilera-Olivares D, Palma V, Zapata V, Flores-Prado L, Niemeyer HM, submitted manuscript); it would be interesting to assess the genetic relatedness of colonies sharing the same substrate and compare it with the genetic relatedness of colonies from different nesting substrates in order to obtain additional support for the proposal above.

A negative correlation between degree of relatedness and intensity of aggression was also reported in the separate-piece nesting termite Macrotermes subhyalinus (Termitidae) [24]; genetic similarity between major workers - a sub-caste mostly devoted to defense - that were confronted in behavioral bioassays was significantly correlated with the level of aggression, and geographical distance played a major role in determining aggression behaviors [24]. Furthermore, a genetic basis for CC composition was suggested [24], in agreement with previous studies [41, 44, 50, 51]. The situation, however, could be more complex than described above. For example, aggression in the separate-piece nesting termite Coptotermes formosanus (Rhinotermitidae) was not correlated with CC composition nor with genetic relatedness; rather, diet and some particular compounds it contained were found to account for aggression [52]. Overall, these results show the importance that chemical communication, whether through endogenous or exogenous compounds, has in termite biology.

\section{Conclusions}

- Nestmate recognition mediated by cuticular compounds was shown by soldiers of $N$. chilensis (a one-piece nesting termite) confronted with conspecific dealates.

- Genetic results suggest than kin recognition occurs in soldiers of $N$. chilensis.

- These results are relevant in order to complete the gap of knowledge on conspecific recognition in onepiece nesting termites, and show for the first time such recognition in soldiers confronted with dealates, making it possible to infer the role of the former under a potential risk of invasion into the colony.

\section{Acknowledgements}

This work was financially supported by FONDECYT grant 1120210 to HMN, CONICYT grant 79100013 to LF-P, CONICYT fellowship for PhD studies D- 21080582 to DA-O, and MECESUP internship program to DA-O.

Funding

This work was financially supported by FONDECYT grant 1120210 to HMN, CONICYT grant 79100013 to LF-P, CONICYT fellowship for PhD studies D-21080582, and MECESUP internship program to DA-O.

Availability of data and materials

Please contact author for data requests. 


\section{Authors' contributions}

DAO: design of experiments, data analysis and interpretation of results, manuscript preparation. JRM: field and laboratory work, data analysis and interpretation of results: CBL: laboratory work, data analysis. LFP: data analysis, interpretation of results. HMN: design of experiments, interpretation of results, manuscript preparation. All authors read and approved the final manuscript.

\section{Competing interests}

The authors declare that they have no competing interests.

\section{Consent for publication}

Not applicable.

\section{Ethics approval and consent to participate}

Not applicable.

\section{Author details}

'Departamento de Ciencias Ecológicas, Facultad de Ciencias, Universidad de Chile, Casilla 653, Santiago, Chile. ${ }^{2}$ Instituto de Entomología, Universidad Metropolitana de Ciencias de la Educación, 7760197 Santiago, Chile.

Received: 2 June 2016 Accepted: 24 August 2016

Published online: 01 September 2016

\section{References}

1. Hamilton WD. The genetical evolution of social behavior, I. J Theor Biol. 1964;7:1-16

2. Trivers RL. The evolution of reciprocal altruism. Q Rev Biol. 1971;46:35-57.

3. Smith $B$, Breed $M$. The chemical basis for nestmate recognition and mate discrimination on social insects. In: Cardé R, Bell WJ, editors. Chemical ecology of insects 2. New York: Chapman and Hall; 1995. p. 287-317.

4. Breed MD. Recognition pheromones of the honey bee. The chemistry of nestmate recognition. BioScience. 1998:48:463-70.

5. Breed MD, Guzmán-Novoa E, Hunt GJ. Defensive behaviour of honey bees: organization, genetics, and comparisons with other bees. Annu Rev Entomol. 2004;49:271-98.

6. Gamboa GJ. Kin recognition in eusocial wasps. Ann Zool Fenn. 2004;41: 789-808.

7. Richard F-J, Hunt JH. Intracolony chemical communication in social insects. Insect Soc. 2013:60:275-91.

8. Šobotník J, Hanus R, Roisin Y. Agonistic behavior of the termite Prorhinotermes canalifrons (Isoptera: Rhinotermitidae). J Insect Behav. 2008; 21:521-34

9. Abe T. Evolution of life types in termites. In: Kawano S, Connell JH, Hidaka T, editors. Evolution and Coadaptation in Biotic Communities. Tokyo: University of Tokyo Press; 1987. p. 126-48.

10. Shellman-Reeve JS (1997) The spectrum of eusociality in termites. In: Choe JC, Crespi BJ (eds) The evolution of social behavior in insects and arachnids. Cambridge University Press; 1997. p. 52-93.

11. Donovan SE, Eggleton P, Bignell DE. Gut content analysis and a new feeding group classification of termites (Isoptera). Ecol Entomol. 2001;26: 356-66.

12. Eggleton P. An Introduction To Termites: Biology, Taxonomy And Functional Morphology. In: Bignell DE, Roisin Y, Lo N, editors. Biology of termites: a modern synthesis. New York: Springer; 2011. p. 1-26.

13. Korb J, Hartfelder K. Life history and development - a framework for understanding developmental plasticity in lower termites. Biol Rev. 2008;83: 295-313.

14. Roisin Y, Korb J. Social organisation and the status of workers in termites. In Bignell DE, Roisin Y, Lo N, editors. Biology of termites: a modern synthesis. New York: Springer; 2011. p. 133-64.

15. Nutting WL. Colonizing flights and associated activities of termites. I. The desert damp-wood termite Paraneotermes simplicicornis (Kalotermitidae). Psyche. 1966;73:131-49.

16. Nutting WL (1969) Flight and colony foundation. In: Krishna K, Weesner FM (eds) Biology of termites. Academic Press, New York, Vol. I: pp 233-282

17. Costa-Leonardo AM, Barsotti RC. Swarming and incipient colonies of Coptotermes havilandi (Isoptera: Rhinotermitidae). Sociobiology, 1998:31:131-42.
18. Ripa R, Luppichini P. Especies de termites de importancia económica en presentes en Chile. In: Rippa R, Luppichini P, editors. Termitas y otros insectos xilófagos en Chile: especies, biología y manejo. Santiago, Chile: Colección libros INIA; 2004. p. 73-105.

19. Fuchs A, Schreyer A, Feuerbach S, Korb J. A new technique for termite monitoring using computer tomography and endoscopy. Int J Pest Manage. 2004;50:63-6.

20. Himmi SK, Yoshimura T, Yanase Y, Oya M, Torigoe T, Imazu S. X-ray tomographic analysis of the initial structure of the royal chamber and the nest-founding behavior of the drywood termite Incisitermes minor. J Wood Sci. 2014:60:453-60.

21. Clément $J$, Bagnères AG. Nesmate recognition in termites. In: VanderMeer RK, Breed MD, Winston ML, Espalie KE, editors. Pheromone communication in social insects: ants, wasps, bees, and termites. Oxford: Westview Press; 1998. p. 126-55.

22. Haverty MI, Copren KA, Getty GM, Lewis VR. Agonistic behavior and cuticular hydrocarbon phenotypes of colonies of Reticulitermes (Isoptera: Rhinotermitidae) from Northern California. Ann Entomol Soc Am. 1999;92:269-77.

23. Kaib M, Franke S, Francke W, Brandl R. Cuticular hydrocarbons in a termite: phenotypes and a neighbour-stranger effect. Physiol Entomol. 2002;27:189-98.

24. Kaib M, Jmhasly P, Wilfert L, Durka W, Franke S, Francke W, Leuthold RH, Brandl R. Cuticular hydrocarbons and aggression in the termite Macrotermes subhyalinus. J Chem Ecol. 2004;30:365-85.

25. Uva P, Clément JL, Bagnères AG. Colonial and geographic variations in agonistic behaviour, cuticular hydrocarbons and mtDNA of Italian populations of Reticulitermes lucifugus (Isoptera, Rhinotermitidae) Insect Soc. 2004;51:163-170.

26. Costa-Leonardo AM, Casarin FE, Lima JT. Chemical communication in Isoptera. Neotrop Entomol. 2009:38:1-6.

27. Van Zweden JS, d'Ettorre P. Nestmate recognition in social insects and the role of hydrocarbons. In: Blomquist GJ, Bagnères AG, editors. Insect hydrocarbons: biology, biochemistry, and chemical ecology. Cambridge UK: Cambridge University Press; 2010. p. 222-43.

28. Blumstein DT, Daniel JC, Evans CS. Quantifying behavior the JWatcher way Sunderland, Massachusetts: Sinauer Associates, Inc.; 2007.

29. Haverty MI, Thorne BL. Agonistic behavior correlated with hydrocarbon phenotypes in dampwood termites, Zootermopsis (Isoptera: Termopsidae). J Insect Behav. 1989;2:523-43.

30. Bagnères $A G$, Killian $A$, Clément $J L$, Lange $C$. Interspecific recognition among termites of the genus Reticulitermes: Evidence for a role for the hydrocarbons. J Chem Ecol. 1991;17:2397-420.

31. Jmhasly P, Leuthold RH. Intraspecific colony recognition in the termites Macrotesmes subhyalinus and Macrotermes bellicosus (Isoptera, Termitidae). Insect Soc. 1999:46:164-70

32. Cornelius ML, Osbrink WLA. Agonistic interactions between colonies of the Formosan subterranean termite (Isoptera: Rhinotermitidae) in New Orleans, Louisiana. Environm Entom. 2003;32:1002-9.

33. Roulston TH, Buczkowski G, Silverman J. Nestmate discrimination in ants: effect of bioassay on aggressive behavior. Insect Soc. 2003;50:151-9.

34. Lorenzi MC, Bagnères AG, Clément J-L, Turillazzi S. Polistes biglumis bimaculatus epicuticular hydrocarbons and nestmate recognition (Hymenoptera: Vespidae). Insect Soc. 1997:44:123-38.

35. Flores-Prado L, Aguilera-Olivares D, Niemeyer HM. Nest-mate recognition in Manuelia postica (Apidae: Xylocopinae): an eusocial trait is present in a solitary bee. P Roy Soc B. 2008;275:285-91.

36. Siegel S, Castellan Jr NJ. Nonparametric statistics for the behavioral sciences. 2nd ed. New York: McGrawHill International Editions; 1988.

37. StatSoft Inc. STATISTICA (data analysis software system), version 7. 2004. www.statsoft.com. Accessed 4 Dec 2015.

38. Aguilera-Olivares D, Flores-Prado L, Véliz D, Niemeyer HM. Mechanisms of inbreeding avoidance in the one-piece drywood termite Neotermes chilensis. Insect Soc. 2015;62:237-45.

39. Goodnight KF, Queller DC. Computer software for performing likelihood tests of pedigree relationship using genetic markers. Mol Ecol. 1999;8:1231-4.

40. Connétable $S$, Robert $A$, Bouffault $F$, Bordereau C. Vibratory alarm signals in two sympatric higher termite species: Pseudacanthotermes spiniger and $P$. militaris (Termitidae, Macrotermitinae). J Insect Behav. 1999:12:329-42.

41. Traniello JFA. Enemy deterrence in the recruitment strategy of a termite: soldier-organized foraging in Nasutitermes costalis. Proc Nat Acad Sci USA 1981;78:1976-9.

42. Adams E. Nest-mate recognition based on heritable odors in the termite Microcerotermes arboreus. Proc Natl Acad Sci USA. 1991;88:2031-4. 
43. Takahashi S, Gassa A. Roles of cuticular hydrocarbons in intra- and interspecific recognition behavior of two Rhinotermitidae species. J Chem Ecol. 1995;21:1837-45.

44. Husseneder C, Brandl R, Epplen C, Epplen JT, Kaib M. Variation between and within colonies in a termite: Morphology, genomic DNA, and behaviour. Mol Ecol. 1998;7:983-90.

45. Kirchner WH, Minkley N. Nestmate discrimination in the harvester termite Hodotermes mossambicus. Insect Soc. 2003;50:222-5.

46. Marins A, DeSouza O. Nestmate recognition in Cornitermes cumulans termites(Insecta: Isoptera). Sociobiology. 2008;51:255-63.

47. Thorne BL, Breisch NL, Muscedere ML. Evolution of eusociality and the soldier caste in termites: Influence of intraspecific competition and accelerated inheritance. Proc Nat Acad Sci USA. 2003;100:12808-13.

48. Aguilera-Olivares D, Burgos-Lefemil C, Melendez W, Flores-Prado L, Niemeyer HM. Chemical basis of nestmate recognition in a defense context in a one-piece nesting termite. Chemoecology. 2016;in press. doi: 10.1007/ s00049-016-0217-x

49. Schwarz MP, Blows MW. Kin association during nest founding in the bee Exoneura bicolor: active discrimination, philopatry and familiar landmarks. Psyche. 1991;98:241-50.

50. Husseneder C, Kaib M, Epplen C, Epplen JT, Brandl R. Small scale population structure of the termite Schedorhinotermes lamanianus: Aggression modulated by genetic and environmental factors. Mitt dtsch Gesell allg angew Ent. 1997;11:183-7.

51. Dronnet S, Lohou C, Christides JP, Bagnères AG. Cuticular hydrocarbon composition reflects genetic relationship among colonies of the introduced termite Reticulitermes santonensis Feytaud. J Chem Ecol. 2006;32:1027-42.

52. Florane CB, Bland JM, Husseneder C, Raina AK. Diet-mediated inter-colonial aggression in the formosan subterranean termite Coptotermes formosanus. J Chem Ecol. 2004;30:2559-74.

\section{Submit your next manuscript to BioMed Central and we will help you at every step:}

- We accept pre-submission inquiries

- Our selector tool helps you to find the most relevant journal

- We provide round the clock customer support

- Convenient online submission

- Thorough peer review

- Inclusion in PubMed and all major indexing services

- Maximum visibility for your research

Submit your manuscript at www.biomedcentral.com/submit 